\title{
DESIGN OF A LOW COST COMPACT SIZE STARTER FOR LOW POWER WATER PUMPS
}

\author{
Santosh K. Verma ${ }^{1}$, Amit Pal ${ }^{2}$ \\ ${ }^{1}$ M.Tech, Electrical Engineering, NIT Agartala, Tripura, India \\ ${ }^{2}$ M.Tech, Electrical Engineering, NIT Agartala, Tripura, India
}

\begin{abstract}
In rural parts of India voltage fluctuation is a very common phenomenon because of the unbalanced load. Sometimes this leads to rapid switching of the water pump installed in the household which may burn/damages the coil because of the overheating, as low power pumps doesn't come with overheating protection. But if we use a starter with water pump then we can reduce its failure probability to a greater extent but generally people prefer online starting of those pumps as they are very low powered to avoid cost and complexity in installment. Here we have proposed a low cost and very compact size model of a starter which can be designed using very cheap and easily available components. It can be integrated with the pump by the manufacturer during the manufacturing to minimize the failure probability.
\end{abstract}

Keywords: Motor Starter, Automation, Induction Machine, Reduce Voltage Starter, Soft Starting, Water Pump etc...

\section{INTRODUCTION}

During the starting of any induction machine an inrush current flow through the coil of the machine which normally can be up to 5-6 times or even more of the full load current [1]. Although this inrush current flows for a very short duration (till the machine achieves its rated speed) ${ }^{[2]}$ and don't make any great impact on the system's failure but if we turn ON and OFF the machine rapidly then this inrush current may cause overheating of the coil which leads to the failure of machine. There are various techniques and ways to reduce this inrush current in the time of start up i.e. reduced voltage starting.

As we know that current and voltage both are related to each other by ohm's law:

$$
\mathbf{V}=\mathbf{I R}
$$

So if we reduce the voltage then the circuit current will also be reduced in a proportional ratio, ${ }^{[3]}$ hence if we reduce the terminal voltage at the time of starting then we can reduce the inrush current.

In reduced voltage starting technique, we apply a voltage lower than the rated voltage for starting and then we gradually increase the voltage up to the rated voltage to minimise the inrush current at the time of starting.

Here also in our proposed model, we are using the same reduced voltage starting technique to minimise the inrush current and for the smooth starting of the machine. 


\section{PROPOSED CIRCUIT DIAGRAM}

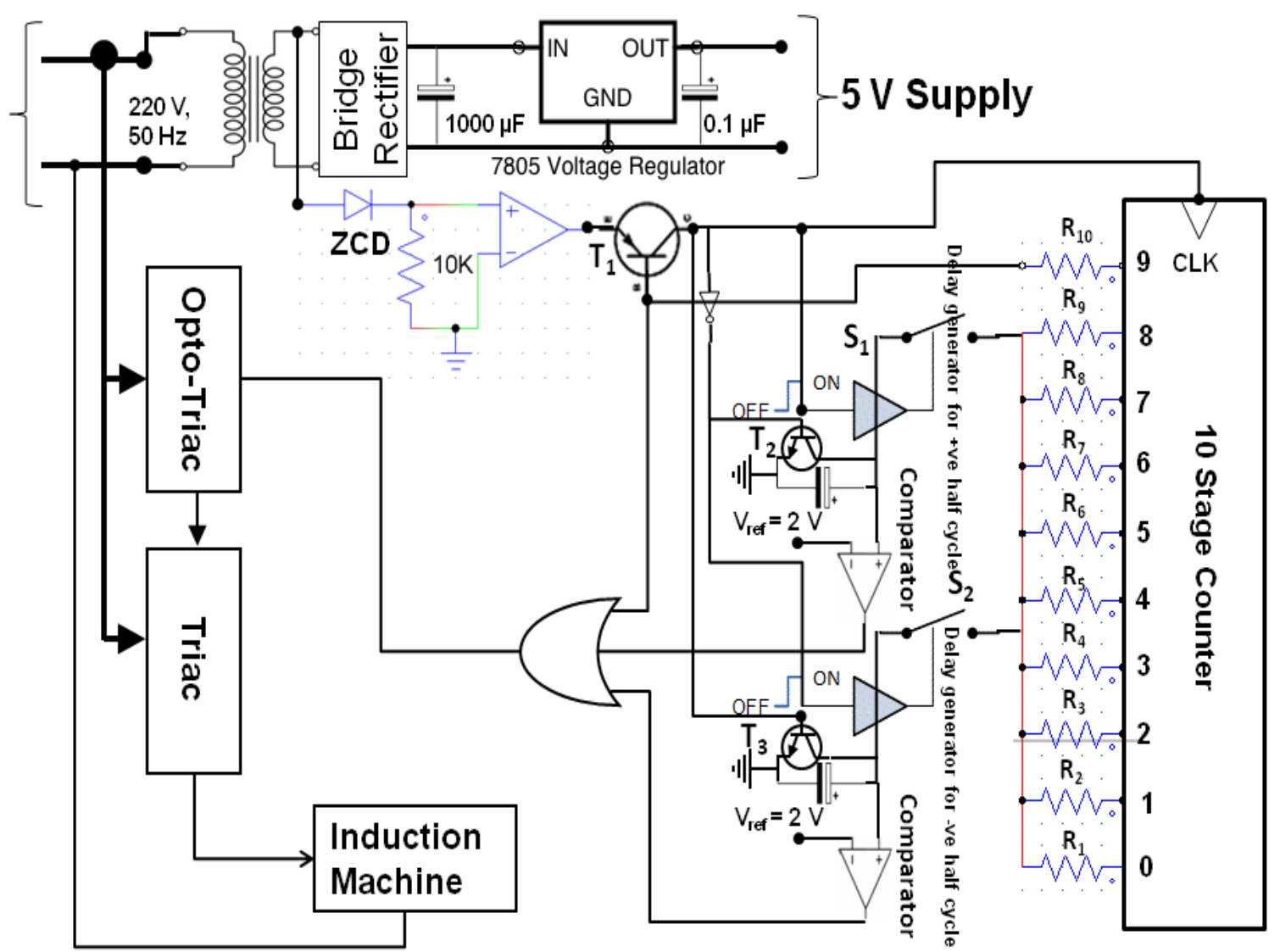

Fig-1: Proposed Circuit Diagram

\section{WORKING OF THE CIRCUIT}

Working of the device can be explained in the following sections:

Power Supply Section: This part is dedicated to provide the $5 \mathrm{~V}$ regulated power supply to the system. For that we have used a suitable step down transformer and its output is fed to the bridge rectifier circuit. Then it is connected to a $1000 \mu \mathrm{F}$ capacitor for smoothing purpose and a 7805 to get the regulated $5 \mathrm{~V}$ power supply from the bridge rectifier circuit. We have connected $0.1 \mu \mathrm{F}$ capacitor at the output of the 7805 to reduce high frequency noise in the output voltage ${ }^{[4]}$.

Zero Crossing Detector Circuit: This part of the circuit is dedicated to provide the clock information for the system i.e. counter. Counter increments its count value by 1 after each cycle i.e. $20 \mathrm{~ms}$ and after every cycle we increase the terminal voltage by $5 \%$. We have not used any other timer source to reduce the cost of the system as mains supply at 50 $\mathrm{Hz}$ is itself a very good source of clock source having time period of $20 \mathrm{~ms}$ and $50 \%$ duty cycle. It can be observed from the output of the ZCD circuit given below (simulated in PSIM).

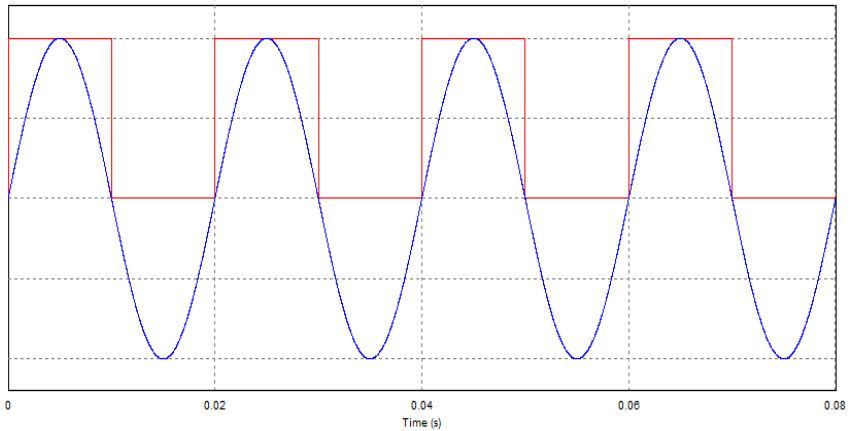

Fig-2: Output from ZCD Circuit

10 Stage Counter: The output from ZCD circuit provides the clock information to the counter. It increments its value by 1 after every rising edge detected at its CLK input. This clock input to the counter is controlled by a PNP transistor ( $\mathrm{T}_{1}$ in the circuit diagram). Once counter value will reach up to its $10^{\text {th }}$ state it will turn OFF the $\mathrm{T}_{1}$, and it will stop further counting action of counter. Counter will not get any further clock, so it will hold its last status until we keep power supply switched ON.

Delay Generator Circuit for +ve and -ve Cycle: As we are using reduced voltage starting technique, our objective is to start the machine at lower voltage and then gradually increase it to the rated voltage. We have achieved it by firing TRIAC at the different time. Here in our design, at the 
time of starting $50 \%$ of the input voltage will be applied to the terminal of machine followed by an increment of $5 \%$ after each $20 \mathrm{~ms}$ i.e. after every cycle we increase duty cycle by $5 \%$, so after a time of $200 \mathrm{~ms}$ full rated voltage will be applied at the terminal of the machine.

To achieve this variable duty cycle we have used a capacitor based charging circuit. Here we have connected different valued resistors at the different output pins of counter, which charges a fixed valued capacitor i.e. when the counter's $0^{\text {th }}$ pin will be high the capacitor will be charged using resistor $R_{1}$ and so on, till the counter's $9^{\text {th }}$ output pin will be high, which will make the PNP transistor $\mathrm{T}_{1}$ OFF and no further counting action will take place. It will let $9^{\text {th }}$ output pin high until we switch off the device. As from circuit diagram, it is clear that it will keep firing the Triac in the beginning of each cycle, resulting a full mains voltage across the machine.

Here we have used two charging circuit, one for positive cycle and another for negative cycle of the input voltage. During the positive cycle, switch $\mathrm{S}_{1}$ (solid state analog switch) will be on. It will lead to charging of the capacitor in the delay generator circuit for +ve cycle through the resistor connected to output of the counter. During this +ve cycle, $\mathrm{T}_{3}$ will discharge the capacitor in the delay generator circuit for -ve cycle. Similarly during -ve cycle switch $\mathrm{S}_{2}$ (solid state analog switch) will be on, and leads to charging of the capacitor in the delay generator circuit for -ve cycle through the resistor connected to output of the counter. During this ve cycle, $\mathrm{T}_{2}$ will discharge the capacitor in the delay generator circuit for +ve cycle. Further we are comparing the voltage across the capacitor using a comparator having a $\mathrm{V}_{\text {ref }}$ of $2 \mathrm{~V}$ at its inverting terminal. The reason for using a 2 $\mathrm{V}$ reference voltage is that charging of capacitor remain linear for the voltage range up to $2 \mathrm{~V}$ when charged from a 5 $\mathrm{V}$ supply. It can be observed from the figure below:

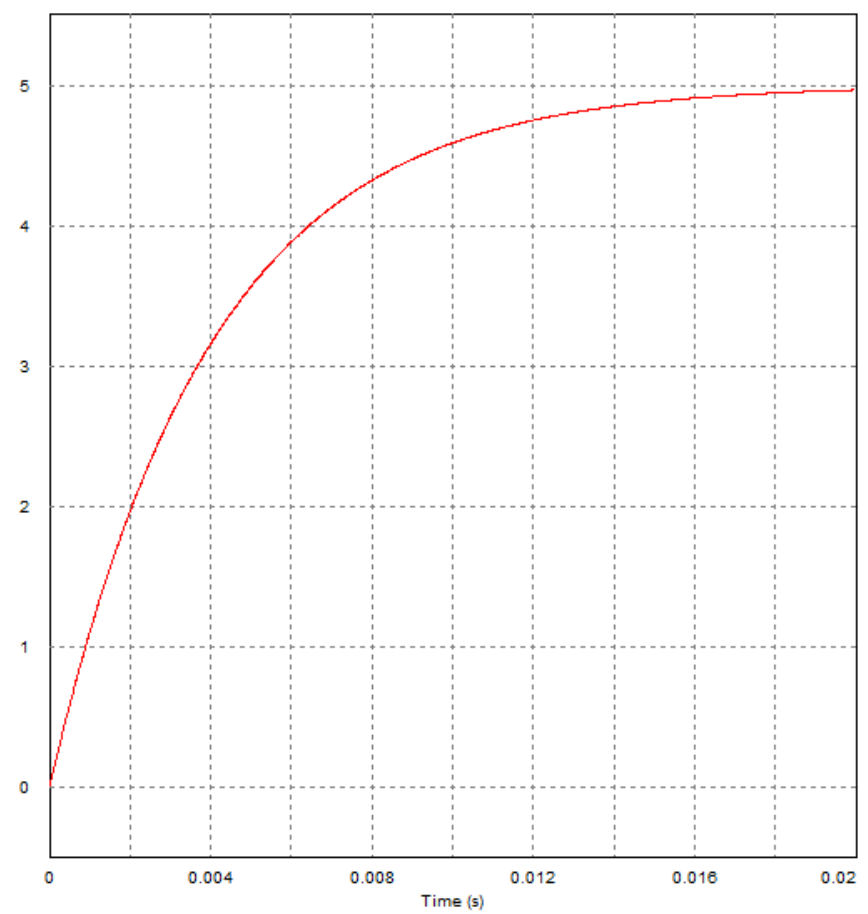

Fig-3: Charging of Capacitor with 5 V Supply

Outputs from the comparators and the $9^{\text {th }}$ output pin of counter are given to the input of an OR gate which triggers an Opto-triac which further triggers Triac to power the machine. So through the charging circuit Triac will be fired at different time lead to supply a variable voltage across the terminal of machine.

\section{CONCLUSION}

Here we have explained that how we can design a low cost starter circuit for the induction machine i.e. water pump. By choosing the appropriate values of resistors and capacitors, one can easily design it in a very low cost. The circuit consists of non programmable parts. So in case if any component fails, anyone can replace it with new ones and if it is installed with the machine it will surely reduce the failure chances.

\section{REFERENCES}

[1] Source Bright Hub Engineering.Availiable: http://www.brighthubengineering.com/hvac/74957starting-methods-for-induction-motors/

[2] "Reduced Voltage Starting of Low Voltage, Three_Phase Squirrel-Cage Induction Motors (Technical Overview),". [Online]. Available: http://static.schneiderelectric.us/docs/Motor\%20Control/8600PD9201.pdf

[3] "Reduced Voltage Starting of Low Voltage, Three_Phase Squirrel-Cage Induction Motors (Technical Overview),". [Online]. Available: http://static.schneider-

electric.us/docs/Motor\%20Control/8600PD9201.pdf

[4] "Datasheet LM7805,". [Online]. Available: https://www.fairchildsemi.com/datasheets/LM/LM78 05.pdf 


\section{BIOGRAPHIES}

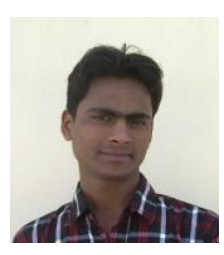

Santosh K. Verma currently in First year

Pursuing (M.Tech) Master of Technology (Electrical Engineering) from "National Institute of Technology, Agartala.

Email- santoshverma2692@gmail.com

Phone No- +91986239889

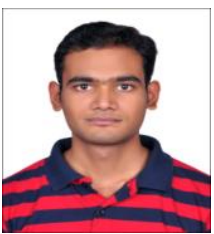

Amit Pal currently in First year Pursuing (M.Tech) Master of Technology (Electrical Engineering) from "National Institute of Technology, Agartala.

Email-amitpal.pdh@gmail.com

Phone No- +9194 24467301 